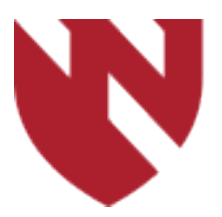

September 2020

\title{
New Finding of Multiple Inflamed Follicular Cysts in Two Patients With CANDLE Syndrome: A Case Report
}

\author{
Tyler Holley \\ University of Nebraska Medical Center \\ Melissa Moutray \\ Private Practice \\ Indranell Bhattacharyya \\ University of Florida \\ Chad S. Sloan \\ University of Nebraska Medical Center \\ Valmont P. Desa \\ University of Nebraska Medical Center
}

Tell us how you used this information in this short survey.

Follow this and additional works at: https://digitalcommons.unmc.edu/gmerj

Part of the Higher Education Commons, and the Medicine and Health Sciences Commons

\section{Recommended Citation}

Holley, T., Moutray, M., Bhattacharyya, I., Sloan, C. S., , Desa, V. P. New Finding of Multiple Inflamed Follicular Cysts in Two Patients With CANDLE Syndrome: A Case Report. Graduate Medical Education Research Journal. 2020 Sep 29; 2(1). https://digitalcommons.unmc.edu/gmerj/vol2/iss $1 / 43$ 
New Finding of Multiple Inflamed Follicular Cysts in Two Patients With CANDLE Syndrome: A Case Report

\section{Creative Commons License}

\section{(c) (1) $\Theta(9$}

This work is licensed under a Creative Commons Attribution-Noncommercial-No Derivative Works 4.0 License. 
Conclusion: In one of the largest studies of prostate cancer in RA, we estimated prostate cancer rates to be similar in a national Veteran population with RA to those in the general population. The small difference may be accounted for by cases not captured within ORD. This study was limited by the indirect standardization of prostate cancer rates to SEER. There is need for future research with direct standardization to US Veterans.

https://doi.org/10.32873/unmc.dc.gmerj.2.1.041

\section{New Finding of Multiple Inflamed Follicular Cysts in Two Patients With CANDLE Syndrome: A Case Report} Tyler J. Holley ${ }^{1}$, Melissa Moutray ${ }^{2}$, Indranell Bhattacharyya ${ }^{3}$, Chad S Sloan ${ }^{1}$, Valmont P Desa ${ }^{1}$

${ }^{1}$ University of Nebraska Medical Center, Department of Surgery, Division of Oral and Maxillofacial Surgery

${ }^{2}$ Oral and Maxillofacial Surgeon, Private Practice, Garden City, KS

${ }^{3}$ University of Florida, Department of Pathology, Division of Oral and Maxillofacial Pathology, Gainesville, FL

Mentor: Valmont P Desa

Program: Oral and Maxillofacial Surgery

Type: Case Report

Background: CANDLE Syndrome (Chronic Atypical Neutrophilic Dermatosis with Lipodystrophy and Elevated Temperature) is an autoinflammatory disease. Characteristics include: recurrent fevers, organ inflammation, skin lesions, anemia, lipodystrophy, basal ganglion calcifications, and delayed physical development. Orofacial manifestations include facial lipodystrophy, swollen eyelids, thick lips, macroglossia, generalized microdontia, and jaw osteopenia. We describe novel cases of two patients, diagnosed with CANDLE syndrome, who presented with radiolucent mandibular lesions associated with displaced permanent molars and mandibular bony expansion.

Methods: Patient 1: A 9-year-old male with CANDLE Syndrome was referred to our clinic for evaluation of a left mandibular radiolucency. After appropriate work-up, the lesion was surgically removed, found to be cystic in characteristic, measured $2 \times 2 \times 0.5 \mathrm{~cm}$ and filled with a dark-brown turbid fluid. Two-years later, the patient returned with complaint of movement of his teeth. Repeat imaging showed a recurrent $3 \times 2 \times 1 \mathrm{~cm}$ lesion.

Patient 2: A 10-year-old male with CANDLE Syndrome was referred to our clinic for radiographic findings of a right mandibular radiolucency. Computed tomography imaging showed a $4 \times 3 \times 1 \mathrm{~cm}$ lesion and an additional $1 \mathrm{x} 1 \mathrm{x} 1 \mathrm{~cm}$ lesion of the left mandibular body (Figure 1).

Results: Histopathologic analysis of all four lesions revealed cysts of follicular odontogenic origin with intense inflammatory cell infiltrate.

with CANDLE Syndrome presenting with inflammatory odontogenic follicular cysts. The inflammatory cell infiltrate coincides with the inflammatory dysregulation of disease and organ inflammation seen globally. The new finding of radiolucent mandibular cystic lesions provides further insight into the extent and characterization of the Syndrome.

https://doi.org/10.32873/unmc.dc.gmerj.2.1.088

Conclusions: To our knowledge, there has not been a previously described case of patients

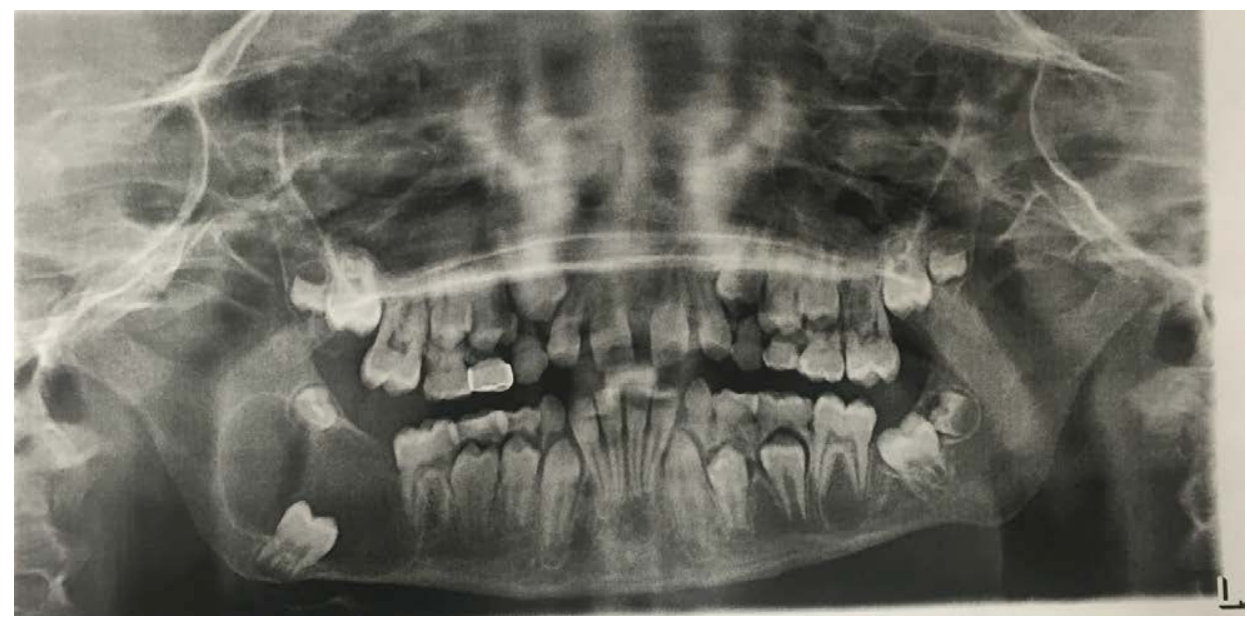

Figure 1. Orthopantomogram demonstrating right and left lesions of the mandible with associated displaced mandibular right second molar and mandibular left first molar, respectively. Additional CT imaging identified right posterior mandibular lesion dimensions of $4 \times 3 \times 1 \mathrm{~cm}$ and left mandibular body lesion of $1 \times 1 \times 1 \mathrm{~cm}$. 